\title{
Les sections bilingues francophones
}

\section{Roger Pilhion}

\section{OpenEdition}

Journals

Édition électronique

URL : http://journals.openedition.org/ries/3974

DOI : $10.4000 /$ ries.3974

ISSN : 2261-4265

\section{Éditeur}

Centre international d'études pédagogiques

\section{Édition imprimée}

Date de publication : 7 septembre 1995

Pagination : 117

ISSN : 1254-4590

\section{Référence électronique}

Roger Pilhion, «Les sections bilingues francophones », Revue internationale d'éducation de Sèvres [En ligne], 07 | 1995, mis en ligne le , consulté le 30 avril 2019. URL : http://journals.openedition.org/ ries/3974 ; DOI : 10.4000/ries.3974

Ce document a été généré automatiquement le 30 avril 2019

(c) Tous droits réservés 


\title{
Les sections bilingues francophones
}

\author{
Roger Pilhion
}

1 Dans le cadre de l'appui à la diffusion de la langue française à l'étranger, le ministère des affaires étrangères privilégie la coopération avec les établissements scolaires étrangers à programmes de français renforcé, dits établissements bilingues francophones.

2 Renouant avec une tradition ancienne de coopération avec des établissements francophones du Proche et du Moyen-Orient fondées par des congrégations religieuses françaises ou par la Mission laïque et bénéficiant aujourd'hui du concours des services culturels français, nos ambassades se sont engagées, au cours des dernières années, dans des programmes de coopération avec des établissements scolaires bilingues implantés dans des pays de l'Union européenne, d'Europe centrale et plus récemment de la péninsule indochinoise.

3 Quelque cinquante-huit mille élèves étrangers bénéficient dans ces établissements d'une formation privilégiée au français, la langue française n'y étant pas seulement langue étrangère mais langue d'enseignement pour une ou plusieurs disciplines.

$4 \mathrm{Si}$, pour les générations en cours de formation, le premier cercle de la francophonie est incontestablement constitué par les élèves suivant une scolarité entièrement ou partiellement en français - situation qui correspond à la majorité des pays francophones-, si le deuxième cercle est traditionnellement occupé par les établissements français à l'étranger qui accueillent plus de cent mille élèves étrangers (établissements gérés par l'Agence pour l'enseignement français à l'étranger), ces établissements francophones constituent indubitablement un troisième cercle tout à fait porteur pour le rayonnement de la langue et de la culture françaises hors des limites traditionnelles de la francophonie.

\section{Répartition géographique}

Europe de l'Ouest : Allemagne, Italie, Finlande ; la création de sections bilingues en Europe entre dans le cadre de la promotion du plurilinguisme et du pluralisme culturel (cinquante-six établissements, neuf mille élèves); 
6 Europe centrale et orientale: Bulgarie, Roumanie, Pologne, Hongrie, Slovaquie, République tchèque, Russie et bientôt Arménie; la demande importante d'enseignement bilingue correspond à la volonté locale d'ouverture aux systèmes éducatifs occidentaux et vise à une intégration future à l'Union européenne (cent quinze établissements, neuf mille huit cents élèves) ;

7 Proche et Moyen Orient : Liban, Égypte, Israël, Turquie ; les filières bilingues, d'implantation ancienne souvent religieuse, connaissent actuellement un regain d'intérêt (quarante-neuf établissements, trente-cinq mille élèves, auxquels il faut ajouter trois cents mille élèves scolarisés dans les établissements libanais);

8 Asie du Sud-Est: Vietnam, Cambodge et bientôt Laos; il s'agit d'un phénomène nouveau, répondant à la fois à une volonté française, à l'adhésion de ces pays à la Communauté francophone et au besoin local de filières d'excellence au sein de systèmes éducatifs en crise (cent cinquante classes bilingues, environ quatre mille cinq cents élèves).

\section{Partenariat}

9 Ministères locaux de l'éducation, ministère français de l'éducation nationale, centres de formation et établissements scolaires, Association des universités partiellement ou entièrement de langue française et Université des réseaux d'expression française (AUPELF-UREF) et l'Agence de coopération culturelle et technique (ACCT).

\section{AUTEUR}

\section{ROGER PILHION}

Sous-directeur de la politique linguistique et éducative, direction générale des relations culturelles, scientifiques et techniques, ministère des affaires étrangères, Paris, France 